International Journal of Environmental Research and

Public Health

ISSN 1660-4601

www.mdpi.com/journal/ijerph

Article

\title{
An Assessment of the Interindividual Variability of Internal Dosimetry during Multi-Route Exposure to Drinking Water Contaminants
}

\section{Mathieu Valcke ${ }^{1,2}$ and Kannan Krishnan ${ }^{1, *}$}

1 Département de santé environnementale et santé au travail, Université de Montréal, CP 6128, Succursale Centre-Ville, Montréal, Québec, H3C 3J7, Canada;

E-Mail: mathieu.valcke@inspq.qc.ca

2 Institut national de santé publique du Québec, 190 Boulevard Crémazie Est, Montréal, Québec, H2P 1E2, Canada

* Author to whom correspondence should be addressed; E-Mail: kannan.krishnan@umontreal.ca; Tel.: +1-514-343-6581; Fax: +1-514-343-2200.

Received: 9 October 2010; in revised form: 4 November 2010 / Accepted: 12 November 2010 / Published: 17 November 2010

\begin{abstract}
The objective of this study was to evaluate inter-individual variability in absorbed and internal doses after multi-route exposure to drinking water contaminants (DWC) in addition to the corresponding variability in equivalent volumes of ingested water, expressed as liter-equivalents (LEQ). A multi-route PBPK model described previously was used for computing the internal dose metrics in adults, neonates, children, the elderly and pregnant women following a multi-route exposure scenario to chloroform and to tri- and tetra-chloroethylene (TCE and PERC). This scenario included water ingestion as well as inhalation and dermal contact during a 30-min bathroom exposure. Monte Carlo simulations were performed and distributions of internal dose metrics were obtained. The ratio of each of the dose metrics for inhalation, dermal and multi-route exposures to the corresponding dose metrics for the ingestion of drinking water alone allowed computation of LEQ values. Mean BW-adjusted LEQ values based on absorbed doses were greater in neonates regardless of the contaminant considered $(0.129-0.134 \mathrm{~L} / \mathrm{kg}$ BW), but higher absolute LEQ values were obtained in average adults (3.6-4.1 L), elderly (3.7-4.2 L) and PW (4.1-5.6 L). LEQ values based on the parent compound's AUC were much greater than based on the absorbed dose, while the opposite was true based on metabolite-based dose metrics for chloroform and TCE, but not PERC. The consideration
\end{abstract}


of the 95th percentile values of BW-adjusted LEQ did not significantly change the results suggesting a generally low intra-subpopulation variability during multi-route exposure. Overall, this study pointed out the dependency of the LEQ on the dose metrics, with consideration of both the subpopulation and DWC.

Keywords: drinking water contaminants; inter-individual variability; liter-equivalents; multi-route exposure; physiologically-based pharmacokinetic modeling

\section{Introduction}

When establishing drinking water guidelines (DWG, in $\mathrm{mg} / \mathrm{L}$ ) of chemical contaminants on the basis of non-carcinogenic effects, regulatory agencies account for the average daily ingestion rate of water (IRW, L/day) by an adult [1]:

$$
\mathrm{DWG}=\frac{\mathrm{TRV} \times \mathrm{BW} \times \mathrm{RCS}}{\mathrm{IRW}}
$$

where TRV is the toxicological reference value (in $\mathrm{mg} / \mathrm{kg}$ BW_day), BW is the body weight of an average adult (i.e., $70 \mathrm{~kg}$ ), and RCS is the relative source contribution (20\% by default) of drinking water to total exposure. For several drinking water contaminants (DWC) that are volatile and/or lipophilic, exposure can also result from the inhalation of vapors emitted from water as well as from the dermal contact during water usage for hygiene and domestic purposes. Such "multi-route exposure" has been well documented for trichloroethylene (TCE) and chloroform based on experimental data as the absorbed dose resulting from the inhalation of vapors and the dermal exposure to water could actually equal or even exceed the absorbed dose resulting from the ingestion of drinking water [2-7]. These results were also confirmed by dose estimates [8] and physiologicallybased pharmacokinetic (PBPK) modeling [9]. Deterministic PBPK modeling has also been used to evaluate the contribution of inhalation and dermal exposure to internal doses and/or cancer risk of chloroform [10], tetrachloroethylene (PERC, [11]) and methyl-t-butyl-ether (MTBE, [12]).

The notion of "liter equivalent" (LEQ) has been defined as the amount of water that needs to be ingested to absorb an equivalent dose of DWC by other routes of exposure (i.e., inhalation, dermal). As an example, an adult's inhalation exposure to chloroform during an eight-minute shower has been estimated to generate an absorbed dose that corresponds to $17 \%$ of the total dose absorbed, which is equivalent to ingesting $0.46 \mathrm{~L}$ of water [8]. In addition, a ten-minute shower generated a LEQ of 0.50-0.57 L [6,9]. Dermal exposure has been estimated to contribute to 19 and $31 \%$ of the total absorbed dose in adults during a 10- and 30-min shower, respectively [9]. As a result, Haddad et al. [9] determined that multi-route exposure to chloroform, including ingestion, inhalation and dermal contact for 10- and 30-min showers resulted in absorbed doses equivalent to the doses resulting from ingestion of 2.65 and $4.65 \mathrm{~L}$ in a $70 \mathrm{~kg}$ adult. For TCE, values of 2.51 and $4.54 \mathrm{LEQ}$ were respectively reported for 10- and 30-min showers.

LEQ values of 7.2 and 4 have been used by CalEPA [13] and Health Canada [14], respectively, in the establishment of drinking water guidelines for TCE. Also, a value of 4.11 LEQ was determined for 
trihalomethanes on the basis of data for chloroform [15]. For PERC, Health Canada has determined that the contribution of the dermal route is equivalent to that of the oral ingestion [16]. Such values were based on estimates of the absorbed doses in average adults. Haddad et al. [9] showed, however, that the LEQ values differ significantly when based on internal dose metrics (DM) such as the area under the blood concentration versus time curve (AUC) or the amount metabolized (Amet), instead of the absorbed dose. This issue appears important when considering the mode of action of a chemical underlying the toxicological reference values or health guidelines [17].

In addition, multi-route exposure and corresponding calculations of LEQ in subpopulations other than average adults have barely been examined. In this regard, Krishnan and Carrier [18] evaluated the contribution of inhalation and dermal exposure in representative children aged 6, 10 and 14 years, as well as representative adults, by a deterministic PBPK modeling approach. For a 30-min bath, the LEQ values for the sum of inhalation and dermal exposure in these subgroups were 1.45, 1.79, 2.14, and 2.61 LEQ, respectively, for chloroform. For TCE, LEQ values were also determined for a 10 -year old child (1.9 LEQ), a 14-year old adolescent (2.25 LEQ) and a $70 \mathrm{~kg}$ adult (2.41 LEQ). Other subpopulations like pregnant women (PW) or the elderly have not been subjected to such evaluation, even though it appears logical that in the particular case of PW, their high inhalation rates and dermal surface area $[19,20]$ could result in greater BW-adjusted intake of DWC via inhalation or dermal contact.

Therefore, since the inter-individual variability in absorbed and internal doses during multi-route exposure to DWCs has not been evaluated to-date, the objectives of this study were: to evaluate the inter-individual variability in absorbed and internal doses during multi-route exposure to DWC; and to estimate the corresponding variability in LEQ values.

\section{Methods}

The overall method involved using a physiologically-based pharmacokinetic (PBPK) model to compute distributions of LEQ values on the basis of probabilistic distributions of internal DM following a multi-route exposure scenario to known DWCs, namely chloroform and tri- and tetra-chloroethylene (TCE and PERC). Such distributions were obtained in various subpopulations (adults, neonates, children, elderly and pregnant women) by means of Monte Carlo (MC) simulations that account for the variability in the input parameters of the PBPK model.

\subsection{PBPK Model Structure and Parameters for Specific Subpopulations}

The previously published and validated PBPK model [21] for chloroform, TCE and PERC written in Microsoft Excel ${ }^{\circledR}$ (Microsoft Corporation, Seattle, WA) as per Haddad et al. [22] was used for this study. Briefly, this model consists of six basic compartments (liver, fat, skin, kidneys, richly perfused tissues and rest of the body), with a seventh compartment (foeto-placental unit) being added for pregnant women. As a useful feature with regard to the study of interindividual variability in internal dose metrics, the model ensures that physiological parameters are correlated for a given body weight/height, age and gender, while authorizing age-specific variations in the relationships between the physiological parameters and their determinants. To do so, this model framework includes mathematical equations that allow the calculation of physiological parameters as a function of four 
determinants, namely body weight, height, age, and gender. Additionally, a "variability term" based on data of the literature [23-26] is included as a multiplier of the results of selected physiological parameter values calculated with these equations in order to account for the variability in the physiology of two persons of identical age, gender and body mass index. Finally, first order metabolism is considered to occur mainly in the liver, with a minor contribution of kidneys in the case of chloroform and PERC. In computing the metabolism, the model allows the use of catalytic turnover of CYP2E1 (in pmol/mg of microsomal protein, MSP), the isozyme involved in the metabolism of the contaminants investigated and for which data on inter-individual variability are available [27,28].

Table 1 shows the statistics, explained in detail in previous work [21], describing the physiological determinants of the investigated subpopulations. These data were based on the $\mathrm{P}^{3} \mathrm{M}$ database (The Lifeline Group Inc, Annandale, VA) [29], as well as the literature [20,23-28,30-34]. Apart from adults (18-64 years), four presumably sensitive subpopulations were chosen for this study: neonates (birth-30 day), children (1-3 years), elderly (65-90 years) and pregnant women (PW; 38th week of gestation).

Table 1. Probabilistic and deterministic descriptors used to define subpopulation-specific parameters in the PBPK models ${ }^{\text {a) }}$.

\begin{tabular}{|c|c|c|c|c|c|}
\hline $\begin{array}{l}\text { Subpopulation } \\
\text { Median age (range) }\end{array}$ & $\begin{array}{c}\text { Adults } \\
41(18-64)^{(a)}\end{array}$ & $\begin{array}{c}\text { Neonates } \\
14 \mathrm{~d}(0-30 \mathrm{~d})\end{array}$ & $\begin{array}{c}\text { Children } \\
(1-3)^{(a)}\end{array}$ & $\begin{array}{c}\text { Elderly } \\
78(65-90)^{\text {(a) }}\end{array}$ & $\begin{array}{c}\text { Pregnant women } \\
29(15-44)^{(a)}\end{array}$ \\
\hline \multicolumn{6}{|l|}{ Parameter } \\
\hline \multicolumn{6}{|l|}{ PROBABILISTIC VARIABLES ${ }^{(\mathrm{b})}$} \\
\hline $\begin{array}{c}\text { Body weight } \\
(\mathrm{kg}, \text { mean } \pm \mathrm{SD} \text {, range }):\end{array}$ & $\begin{array}{c}76 \pm 17 \\
37-152^{(\mathrm{c})}\end{array}$ & $\begin{array}{c}4 \pm 1 \\
2-7\end{array}$ & $\begin{array}{l}13 \pm 2 \\
7-32^{(c)}\end{array}$ & $\begin{array}{c}72 \pm 16 \\
33-155^{(\mathrm{c})}\end{array}$ & $\begin{array}{l}82 \pm 18 \\
48-166\end{array}$ \\
\hline $\begin{array}{c}\text { Body height } \\
(\mathrm{cm}, \text { mean } \pm \mathrm{SD}, \text { range }):\end{array}$ & $\begin{array}{c}167 \pm 10 \\
144-198^{(\mathrm{c})}\end{array}$ & $\begin{array}{c}46 \pm 16 \\
35-80\end{array}$ & $\begin{array}{c}87 \pm 6 \\
70-106^{(\mathrm{c})}\end{array}$ & $\begin{array}{c}164 \pm 10 \\
138-190^{\text {(c) }}\end{array}$ & $\begin{array}{c}161 \pm 7 \\
132-182^{(\mathrm{c})}\end{array}$ \\
\hline $\begin{array}{c}\text { CYP2E1 concentration } \\
(\mathrm{pmol} / \mathrm{mg} \text { MSP, mean } \pm \mathrm{SD})\end{array}$ & $\begin{array}{c}49 \pm 2 \\
11-130^{(\mathrm{d})}\end{array}$ & $\begin{array}{l}18 \pm 14 \\
1-56\end{array}$ & $\begin{array}{c}42 \pm 18 \\
18-74\end{array}$ & (e) & (e) \\
\hline \multicolumn{6}{|l|}{ DETERMINISTIC VARIABLES } \\
\hline $\begin{array}{l}\text { Glomerular filtration rate } \\
\left(\mathrm{mL} / \mathrm{min} \_1.73 \mathrm{~m}^{2}\right)\end{array}$ & 116.0 & 40.2 & 127.0 & 92.4 & 181.0 \\
\hline $\begin{array}{c}\text { Drinking water ingestion rate } \\
(\mathrm{mL} / \text { day-kg BW })\end{array}$ & 19.9 & 52.4 & 46.8 & 21.8 & 21 \\
\hline REFERENCES & {$[28,30,33]$} & {$[27,32,33]$} & {$[27,33]$} & {$[28,30,33]$} & {$[28,30,31,34]$} \\
\hline
\end{tabular}

Notes: (a) See Valcke and Krishnan [21] for details. (b) Log-normally distributed. (c) $\mathrm{P}^{3} \mathrm{M}$ database (see [29]). (d) Geometric mean \pm geometric standard deviation. (e) Same as for adults. Abbreviations: $\mathrm{BW}=$ body weight; $\mathrm{MSP}=$ microsomal protein; $\mathrm{SD}=$ standard deviation .

\subsection{Exposure Scenarios and Dose Metrics Computed}

For each subpopulation, a multi-route exposure scenario to each drinking water contaminant was simulated. Chemical-specific data taken from the literature are indicated in Table 2. 
Table 2. Chemical-specific parameters for PBPK modeling.

\begin{tabular}{|c|c|c|c|}
\hline \multirow{2}{*}{ Parameters } & \multicolumn{3}{|c|}{ Contaminants } \\
\hline & Chloroform $^{(\mathrm{a})}$ & $\mathrm{TCE}^{(\mathrm{a})}$ & PERC $^{(a)}$ \\
\hline Molecular weight (g/mol) & 119.38 & 131.2 & 165.8 \\
\hline Transfer efficiency in the shower stall & 0.534 & 0.61 & 0.66 \\
\hline \multicolumn{4}{|l|}{ Absorption constants } \\
\hline Oral $\left(\min ^{-1} / \mathrm{kg}^{-0.25}\right)$ & 0.032 & 0.1667 & 0.00216 \\
\hline Dermal (cm/min) & 0.00267 & 0.002 & 0.00207 \\
\hline Urinary excretion constant of TCA $\left(\mathrm{min}^{-1} / \mathrm{kg}^{-0.25}\right)$ & - & 0.0012 & 0.0012 \\
\hline \multicolumn{4}{|l|}{ Partition coefficients } \\
\hline Blood:air & 7.43 & 9.2 & 11.58 \\
\hline Liver:air & 17 & 62.56 & 61.14 \\
\hline Fat:air & 280 & 671.6 & 1449.8 \\
\hline Highly perfused tissues:air & 17 & 62.56 & 58.7 \\
\hline Rest of the body:air & 12 & 21.16 & 70.6 \\
\hline Skin:air & 12 & 20.26 & 275.2 \\
\hline Kidney:air & 11 & - & 58.7 \\
\hline Water:air & 3.66 & 0.83 & 0.79 \\
\hline Placenta:blood & 2.2 & 2.7 & 3.2 \\
\hline \multicolumn{4}{|l|}{ Metabolic constants } \\
\hline Maximal rate $\left(\mu \mathrm{g} / \mathrm{min} / \mathrm{kg}^{0.75}\right)$ & 211.33 & 166.67 & 4 \\
\hline Vmaxc proportionality constant kidney/liver & 0.033 & - & 0.1 \\
\hline Michaelis-Menten $(\mu \mathrm{g} / \mathrm{L})$ & 448 & 1500 & 7700 \\
\hline Fraction of metabolism in TCA & & 0.25 & 0.6 \\
\hline Volume of distribution of TCA & - & $0.1 \times \mathrm{BW}$ & $0.1 \times \mathrm{BW}$ \\
\hline REFERENCES & {$[9,35-38]$} & $\begin{array}{c}{[9,36,37} \\
39-43]\end{array}$ & $\begin{array}{c}{[11,36,37,} \\
39-41,44-46]\end{array}$ \\
\hline
\end{tabular}

Notes: (a) See Valcke and Krishnan [21] for details. Abbreviations: PERC = tetrachloroethylene; $\mathrm{TCA}=$ trichloroacetic acid; TCE $=$ trichloroethylene.

The multi-route scenario considered includes daily ingestion of drinking water (separated into five episodes spaced by a timelag of three hours) as well as inhalation of vapors in the bathroom and dermal contact with water during a once-daily $30 \mathrm{~min}$ bathroom exposure, as per the risk assessment of Health Canada [14,15]. The water-to-air transfer model used in the present study [47], described previously by Haddad et al. [9], does not differentiate the bathroom exposure to chemicals during shower from the bath. As the dermal contact and inhalation exposures are described based on the total volume of water used, the modeling results described here can be applied to both shower and bath. To calculate the air concentration of DWC in the shower stall, a water flow rate of $8.7 \mathrm{~L} / \mathrm{min}$ [11] (rather than $10 \mathrm{~L} / \mathrm{min}$ [47]), was used as this modification resulted in predicted air concentrations that were somewhat closer to the measured data of Jo et al. [3] (not shown).

The dermal surface to be in contact with water during the shower was considered to be $75 \%$ [48]. A $15 \mu \mathrm{g} / \mathrm{L}$ water concentration was retained since it would yield a daily dose of approximately $1 \mu \mathrm{g} / \mathrm{kg} /$ day for a $70 \mathrm{~kg}$ adult as per the risk assessment of Health Canada [14,15]. The computed DM included the total absorbed dose (Dabs), the 24-h area under the arterial blood concentration versus 
time curve for either the parent compound $\left(\mathrm{AUC}_{\mathrm{pc}}\right)$ or stable metabolite $\mathrm{TCA}\left(\mathrm{AUC} \mathrm{met}_{\mathrm{m}}\right.$, for TCE and PERC), and the amount metabolized per $24 \mathrm{~h}$ per L of liver (Amet).

\subsection{Calculation of LEQ Values}

The LEQ values were calculated based on each DM. Thus, the LEQ value based on Dabs was calculated as:

$$
\mathrm{LEQ}=\frac{\mathrm{Dabs}}{[\mathrm{DW}]}
$$

where Dabs is the daily absorbed dose in $\mu \mathrm{g} / \mathrm{kg} \mathrm{BW}$, and [DW] is the concentration in drinking water (i.e., $15 \mu \mathrm{g} / \mathrm{L}$ ), and LEQ is expressed in $\mathrm{L} / \mathrm{kg}$. For the calculation of the LEQ on the basis of internal $\mathrm{DM}$ (i.e., $\mathrm{AUC}_{\mathrm{pc}}, \mathrm{AUC}_{\mathrm{met}}$ or Amet), the ratio of the internal $\mathrm{DM}$ for the multi-route exposure scenario $\left(\mathrm{IDM}_{\mathrm{M}-\mathrm{R}}\right)$ and the internal $\mathrm{DM}$ for the ingestion exposure only (IDM $\left.\mathrm{Ing}_{\mathrm{In}}\right)$ was multiplied by the subpopulation-specific body-weight adjusted drinking water ingestion rate (IngR, in $\mathrm{L} / \mathrm{kg} \mathrm{BW}$ ). It resulted in subpopulation- and DM-specific LEQ values, expressed in BW-adjusted values (L/kg BW):

$$
\mathrm{LEQ}_{\text {IDM }}=\frac{\mathrm{IDM}_{\mathrm{M}-\mathrm{R}}}{\mathrm{IDM}_{\text {Ing }}} \times \operatorname{lngR}
$$

The BW-adjusted LEQ value was then used to calculate the absolute LEQ value (in L) for individuals of a given BW in each subpopulation.

\subsection{Probabilistic Modeling of Internal Dose Metrics for Multi-Route Exposure}

For each subpopulation, MC simulations were performed using Crystal Ball® software (Oracle ${ }^{\mathrm{TM}}$, Redwood Shores, CA) in order to generate statistical distributions of internal DM after 2000 iterations. To avoid unrealistic combinations, $\mathrm{BW}$ and $\mathrm{BH}$ were correlated to $60 \%$ based on population distribution of body mass index in Canada [49]. The resulting DM distributions allowed the evaluation of the variability in internal DM (and corresponding LEQ) for the multi-route exposure scenario. As a measure of this variability, a "variability index" was computed as the ratio between the 95th percentile and (1) the median of DM in each subpopulation ("VI $\mathrm{spop}$ ) and (2) the median in adults ("VI"), for each contaminant investigated. This approach is similar to the approach of WHO on human kinetic adjustment factor (HKAF) [17,50].

\subsection{Sensitivity Analyses}

Sensitivity analyses on the model's input parameters were performed to evaluate to what extent the different assumptions made with regard to these parameters affect the outcome of the model. Based on the impact on $\mathrm{AUC}_{\mathrm{pc}}$, the sensitivity index $(\mathrm{SI})$ for a given parameter $(\mathrm{P})$ was calculated as:

$$
S I=\frac{A U C_{P C_{-} 10}-A U C_{P C_{-} i}}{P_{10}-P_{i}} \times \frac{P_{i}}{A U C_{P C_{-} i}}
$$

where subscript 10 denotes the $\mathrm{AUC}_{\mathrm{pc}}$ and parameter $(\mathrm{P})$ value when the latter is reduced by $10 \%$ compared to the initial value, indicated by subscript $\mathrm{i}$. The greater the resulting SI value, the more 
influential is the parameter on $\mathrm{AUC}_{\mathrm{pc}}$, while positive and negative $\mathrm{SI}$ values are linked to an increase and a decrease in $\mathrm{AUC}_{\mathrm{pc}}$, respectively, when the parameter is increased.

\section{Results}

\subsection{Simulation of Internal Dosimetry for Multi-Route Exposure}

The simulations of multi-route exposure shown in Figure 1 indicate that the neonates would have the highest blood concentration of parent compound as well as the fastest decline post-exposure.

Figure 1. Model simulations of the arterial blood concentration of chloroform (a), TCE (b) and PERC (c) during multi-route exposure in an average adult, neonate, child and pregnant woman (as per Table 1). The elderly are omitted since their profile is almost indistinguishable from an average adult's. The scenario involves a $30 \mathrm{~min}$ bathroom exposure at $\mathrm{t}=1 \mathrm{hr}$ along with five episodes of drinking water ingestion at $\mathrm{t}=2,5,8,11$ and $14 \mathrm{~h}$.

(a)

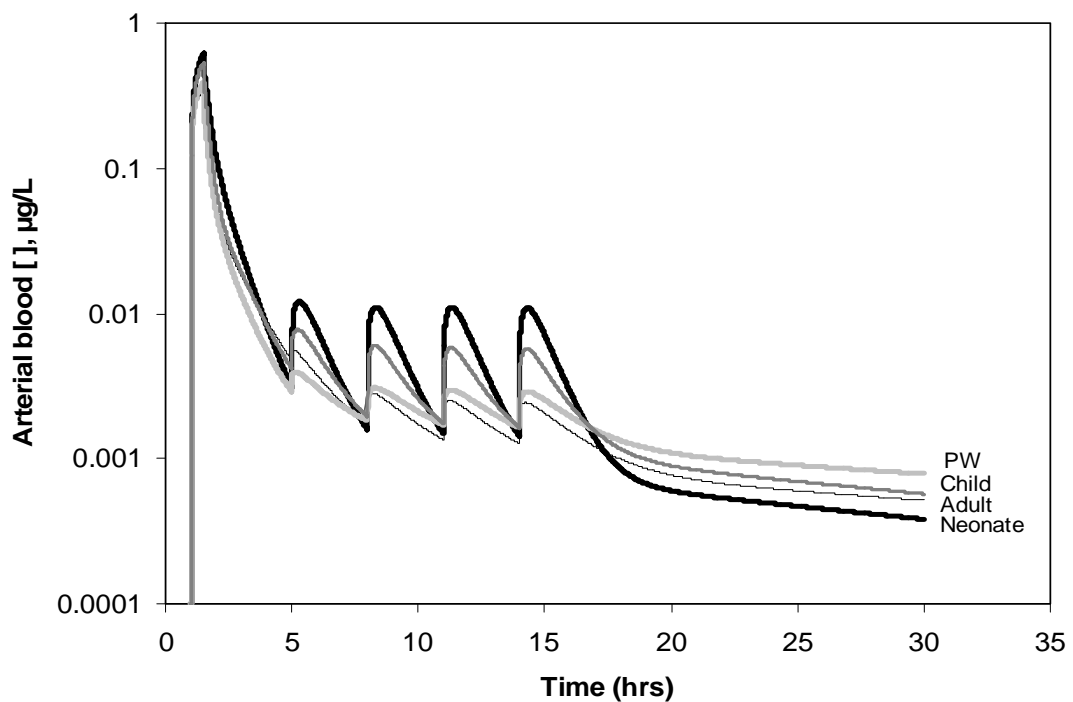

(b)

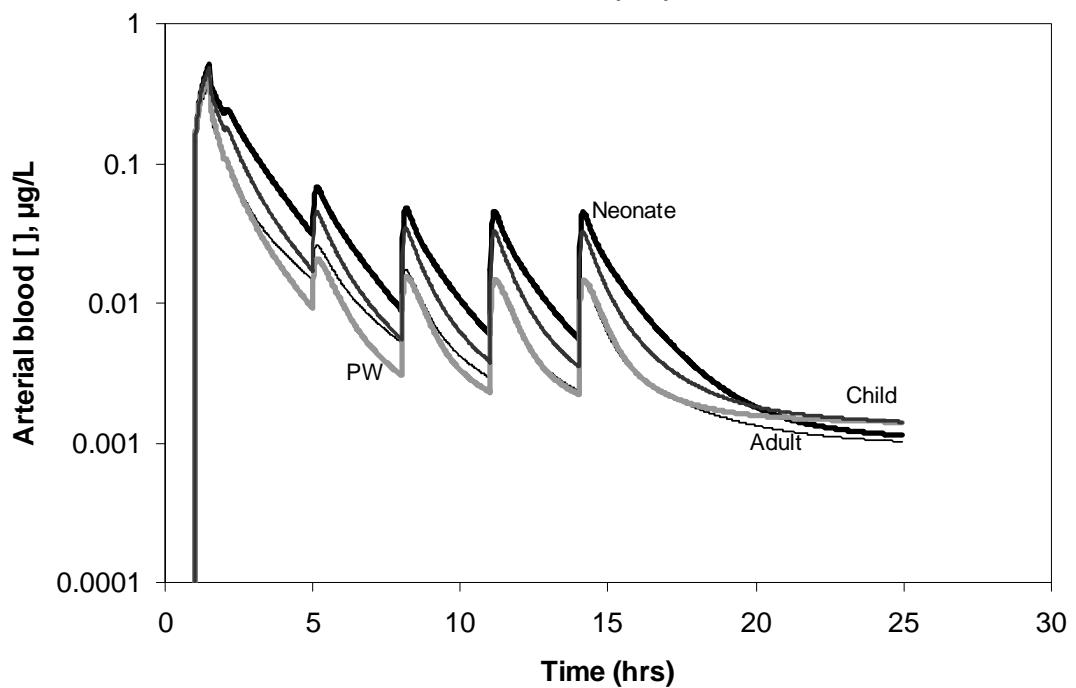


Figure 1. Cont.

(c)

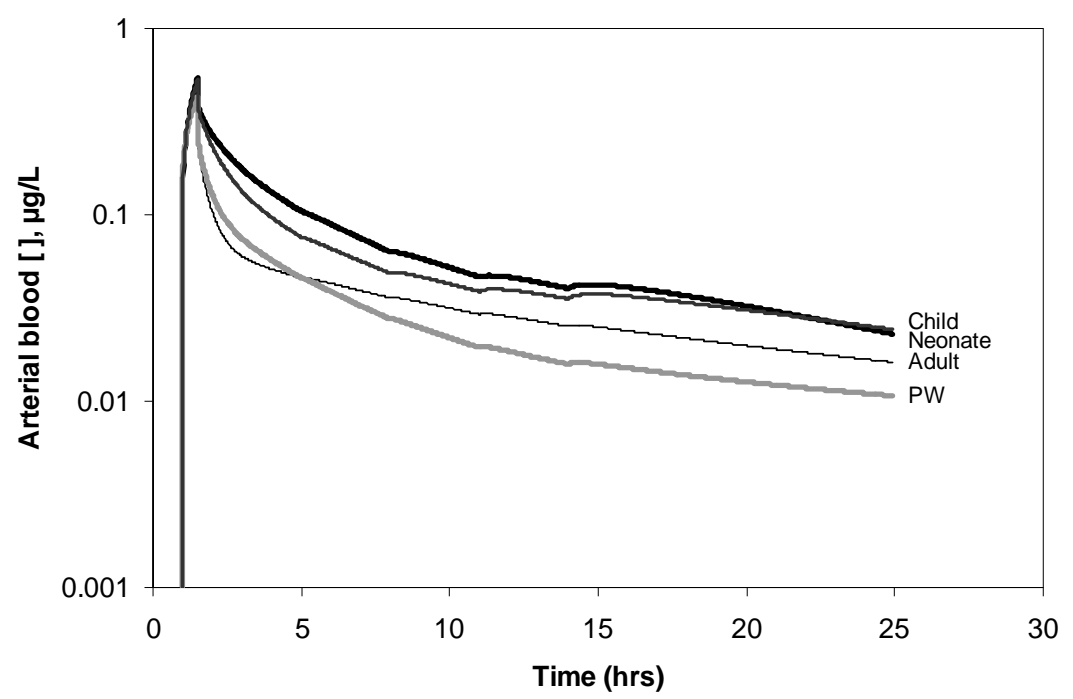

Children would have the second highest blood concentration of the parent compound, while adults and PW would have comparable profiles for chloroform and TCE. Blood concentration of PERC in PW appears constantly lower than that of adults. The contribution of the exposure resulting from the shower is always significant but more so for PERC as the ingestion episodes do not contribute significantly to increased blood levels likely because of its low $\mathrm{K}_{\mathrm{o}}$ value. Conversely, absorption of chloroform and TCE during ingestion is fast, especially for the latter. With regard to TCA (Figure 2), blood concentrations resulting from the exposure to TCE (a) and PERC (b) are clearly greater in respectively the neonate and child than in the other individuals.

Figure 2. Model simulations of the blood concentration of TCA as a metabolite of TCE (a) and PERC (b) during multi-route exposure in average adult, neonate, child, elderly and pregnant woman (as per Table 1). The scenario involves a $30 \mathrm{~min}$ bathroom exposure along with five episodes of drinking water ingestion at $\mathrm{t}=2,5,8,11$ and $14 \mathrm{~h}$.

(a)

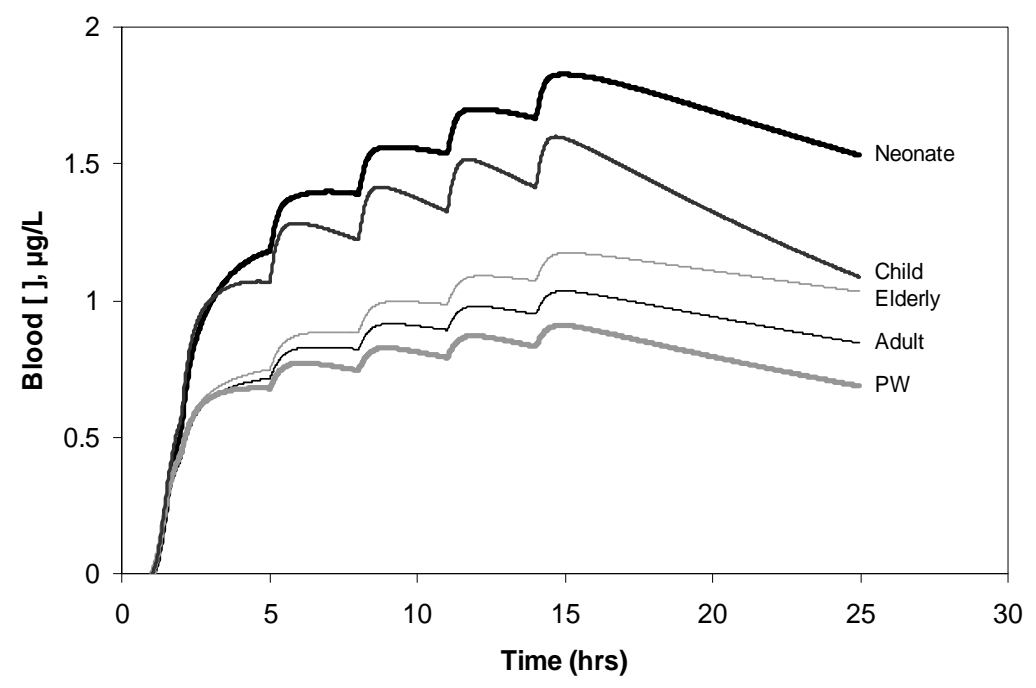


Figure 2. Cont.

(b)

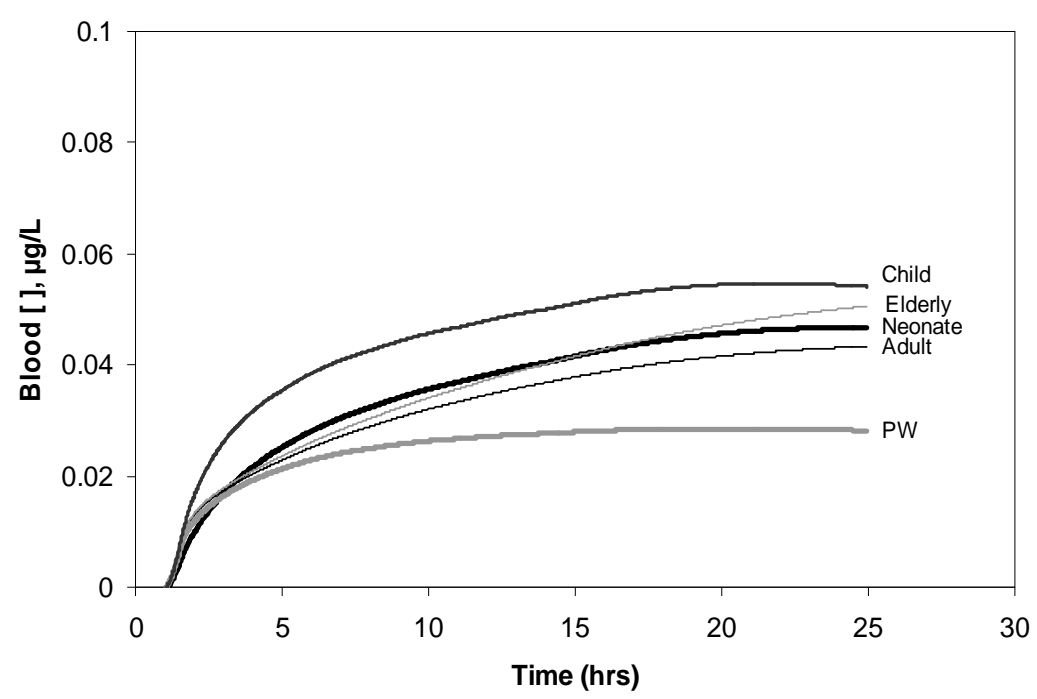

The model results also indicate that elderly would have higher blood levels of TCA than adults and even higher than PW. The contribution of TCE exposure via the shower to blood levels of TCA appears similar to the contribution of the ingestion events and is proportionally more important in the case of TCA produced by the metabolism of PERC.

The results of sensitivity analyses are presented in Figure 3. They clearly show that considering every subpopulation and chemical under study, the most influential parameters of the PBPK models on the $\mathrm{AUC}_{\mathrm{pc}}$ following a multi-route exposure are liver volume and blood flow (for highly metabolized chemicals only), fat volume and blood flow (for PERC) and cardiac output and alveolar ventilation rate for all chemicals and subpopulations. Intrinsic clearance $(=\mathrm{Vmax} / \mathrm{Km})$ is influential for chloroform and TCE, but not for PERC. Although the magnitude of the sensitivity indices varies between the subpopulations for a given parameter, the absolute trend is generally constant. Exceptions are cardiac output $(\mathrm{Qc})$ and alveolar ventilation rates $(\mathrm{Qp})$ in the neonate model for TCE and PERC, as well as for the child in the PERC model only, for which a negative sensitivity index indicates that, contrary to the other subpopulations/chemicals, $\mathrm{AUC}_{\mathrm{pc}}$ decreases when the parameter value increases. 
Figure 3. Sensitivity of parent compound's area under the arterial blood concentration versus time (AUC, $\mu \mathrm{g} / \mathrm{L} \times \mathrm{hs}$ ) to the physiological parameters of the PBPK models for chloroform (a), TCE (b) and PERC (c) in each subpopulation evaluated for a multi-route exposure to water contaminated with $15 \mu \mathrm{g} / \mathrm{L}$. The sensitivity ratios were calculated as the change in $\mathrm{AUC}_{\mathrm{pc}}$ for a $10 \%$ decrease in the value of input parameters (Clint, intrinsic clearance; Qp, alveolar ventilation rate; Qc, cardiac output; Qx, tissue blood flow and Vx tissue volume (l, liver; f, fat; $r$, rest of the body; sk, skin; k, kidney; h, highly perfused)), for a given age, body weight, body height and hepatic content of CYP2E1. In pregnant women, the volume of highly perfused tissues includes the feto-placental unit.

a)

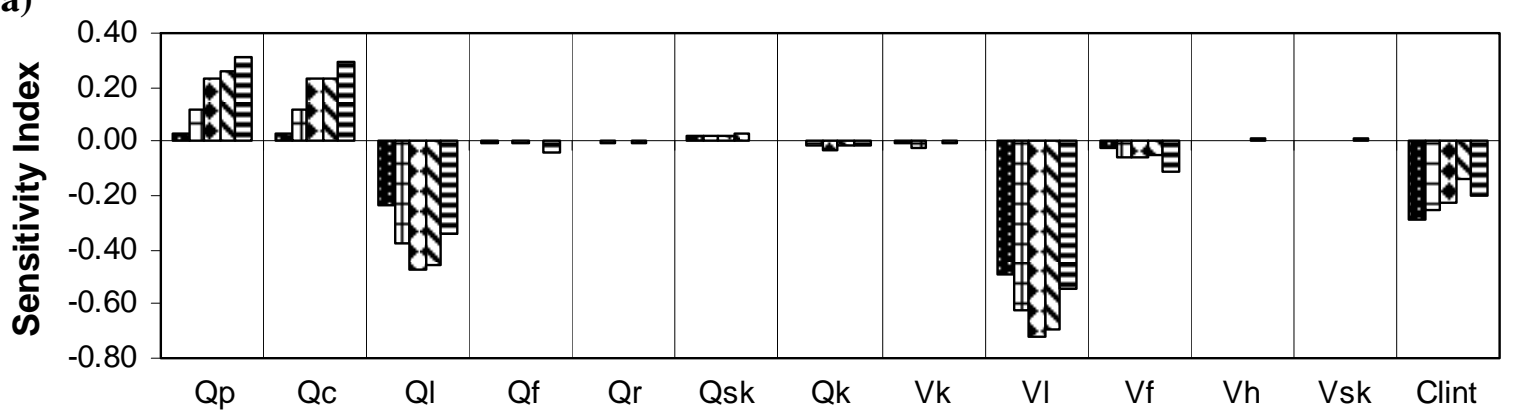

Neonate $\square$ Child $\mathbf{\Delta}$ Adult $\mathbf{\Delta}$ Elderly $\mathbf{E} \mathrm{PW}$

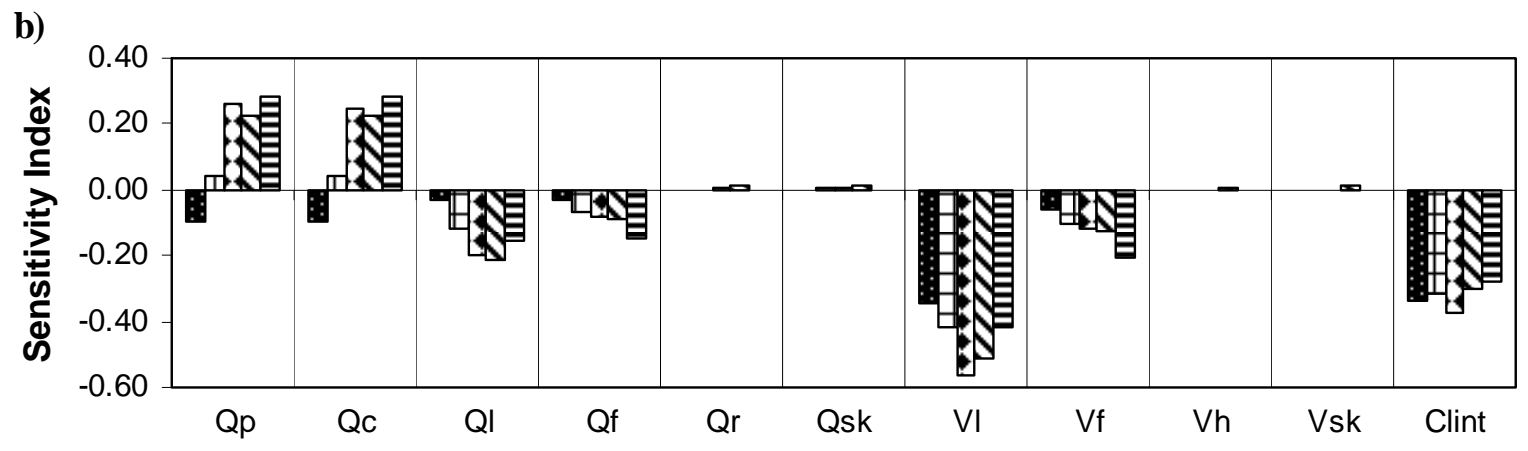

Neonate $\square$ Child $\square$ Adult $\mathbf{\square}$ Elderly $\square$ PW

c)

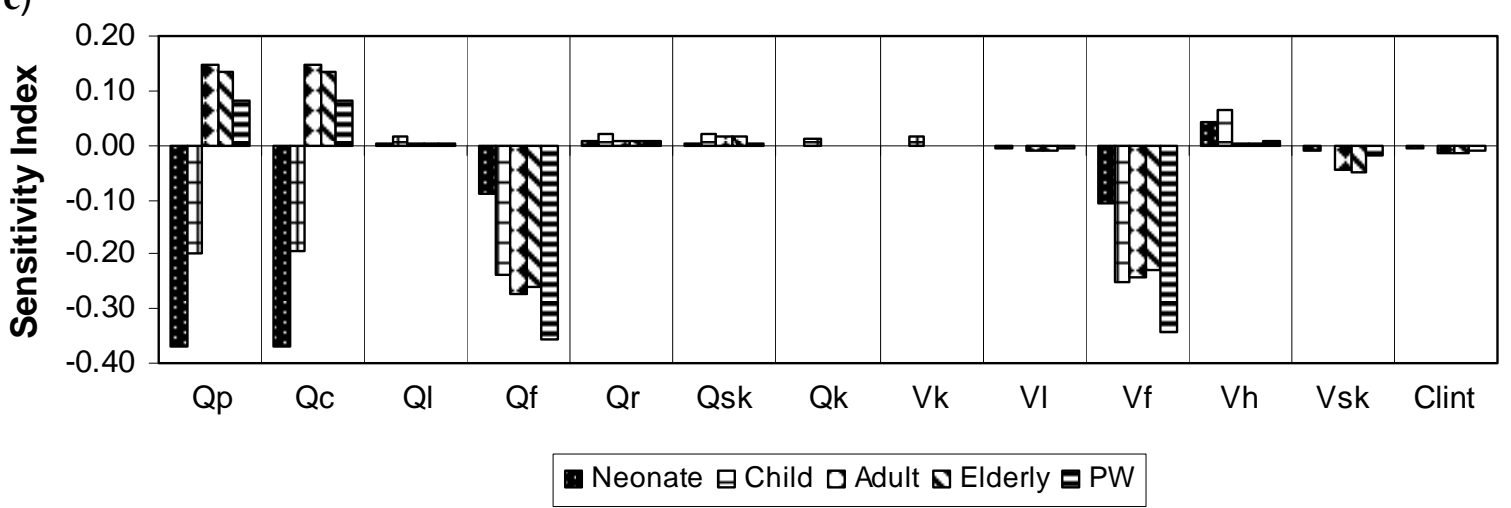

\subsection{Variability of Internal Dosimetry for Multi-Route Exposure}

Table 3 shows the variability of internal DM in each subpopulation for the multi-route exposure. None of the VI, calculated as the ratio of the 95th percentile value of DM in a given subpopulation to 
the median in adults, exceeds the default value of 3.16 used in risk assessment [51]. The intra-group variability (as measured by $\mathrm{VI}_{\text {spop }}$ ) in subpopulations other than adults is almost always lower than the inter-group variability (as measured by VI). The exceptions were: neonates on the basis of $\mathrm{AUC}_{\mathrm{met}}$ for PERC, PW based on $\mathrm{AUC}_{\text {met }}$ for TCE and PERC, and Amet for PERC only. Overall, the greater inter-subpopulation variability based on $\mathrm{AUC}_{\mathrm{pc}}$ and $\mathrm{AUC}_{\text {met }}$ is observed when the neonates are accounted for (VI in the range of 2.07-3.12 $\left(\mathrm{AUC}_{\mathrm{pc}}\right)$ and 2.30-2.52 $\left.\left(\mathrm{AUC}_{\mathrm{met}}\right)\right)$, and when the children are considered (range: 1.94-2.29) with regard to Amet.

Table 3. PDF for internal dose metrics and resulting variability indices (VI) obtained for multi-route exposure scenario in each subgroup.

\begin{tabular}{|c|c|c|c|c|c|c|c|c|}
\hline \multirow{2}{*}{ Subpopulation } & \multicolumn{2}{|c|}{$\underline{\text { Chloroform }}$} & \multicolumn{3}{|c|}{ Trichloroethylene } & \multicolumn{3}{|c|}{ Tetrachloroethylene } \\
\hline & $\begin{array}{c}24-h \\
\text { AUC }_{p c} \\
\end{array}$ & $\begin{array}{c}\text { 24-h } \\
\text { Amet } \\
\end{array}$ & $\begin{array}{c}24-h \\
\text { AUC }_{p c} \\
\end{array}$ & $\begin{array}{c}\text { 24-h } \\
\text { AUC }_{\text {met }} \\
\end{array}$ & $\begin{array}{c}\text { 24-h } \\
\text { Amet } \\
\end{array}$ & $\begin{array}{c}24-h \\
\text { AUC }_{p c} \\
\end{array}$ & $\begin{array}{c}\text { 24-h } \\
\text { AUC }_{\text {met }} \\
\end{array}$ & $\begin{array}{r}\text { 24-h } \\
\text { Amet } \\
\end{array}$ \\
\hline \multicolumn{9}{|l|}{ Adults } \\
\hline Median & 16.4 & 22.5 & 25.4 & 1104 & 20.3 & 50.2 & 41.3 & 0.35 \\
\hline 95th percentile & 21.3 & 27.4 & 36.1 & 1346 & 25.5 & 66.8 & 89.9 & 0.76 \\
\hline$V I$ and $V I_{\text {spop }}$ & 1.30 & 1.22 & 1.37 & 1.22 & 1.26 & 1.33 & 2.18 & 2.17 \\
\hline \multicolumn{9}{|l|}{ Neonates } \\
\hline Median & 32.5 & 31.6 & 58.4 & 1726 & 22.1 & 97.3 & 34.4 & 0.20 \\
\hline 95th percentile & 47.2 & 39.9 & 79.2 & 2539 & 32.7 & 103.8 & 103.9 & 0.57 \\
\hline $\mathrm{VI}_{\text {spop }}$ & 1.45 & 1.26 & 1.36 & 1.47 & 1.48 & 1.07 & 3.02 & 1.25 \\
\hline VI & $\underline{2.89}$ & 1.78 & $\underline{3.12}$ & $\underline{2.30}$ & 1.61 & $\underline{2.07}$ & $\underline{2.52}$ & 1.63 \\
\hline \multicolumn{9}{|l|}{ Children } \\
\hline Median & 23.6 & 37.9 & 39.9 & 1566 & 32.4 & 81.2 & 50.5 & 0.46 \\
\hline 95th percentile & 28.3 & 46.1 & 49.2 & 1866 & 39.4 & 92.1 & 89.9 & 0.80 \\
\hline $\mathrm{VI}_{\mathrm{spop}}$ & 1.20 & 1.22 & 1.23 & 1.19 & 1.22 & 1.13 & 1.78 & 1.74 \\
\hline VI & 1.73 & $\underline{2.05}$ & 1.94 & 1.68 & $\underline{1.94}$ & 1.83 & 2.18 & $\underline{2.29}$ \\
\hline \multicolumn{9}{|l|}{ Elderly } \\
\hline Median & 16.4 & 23.6 & 26.2 & 1222 & 21.3 & 51.2 & 45.8 & 0.36 \\
\hline 95th percentile & 21.4 & 28.0 & 35.6 & 1493 & 27.1 & 67.5 & 96.2 & 0.75 \\
\hline $\mathrm{VI}_{\text {spop }}$ & 1.30 & 1.19 & 1.36 & 1.22 & 1.27 & 1.32 & 2.10 & 2.08 \\
\hline VI & 1.31 & 1.28 & 1.40 & 1.35 & 1.33 & 1.34 & 2.33 & 2.14 \\
\hline \multicolumn{9}{|l|}{ Pregnant women } \\
\hline Median & 17.4 & 26.5 & 26.8 & 976 & 23.4 & 48.6 & 32.8 & 0.34 \\
\hline 95th percentile & 21.9 & 32.9 & 35.4 & 1181 & 29.9 & 60.2 & 68.3 & 0.72 \\
\hline $\mathrm{VI}_{\text {spop }}$ & 1.26 & 1.24 & 1.32 & 1.21 & 1.28 & 1.24 & 2.08 & 2.12 \\
\hline VI & 1.34 & 1.47 & 1.39 & 1.07 & 1.48 & 1.20 & 1.66 & 2.06 \\
\hline
\end{tabular}

Notes: Underlined values denote subgroup with the highest VI for corresponding internal dose surrogate. Italic denotes VIs that are greater than the range defined by the corresponding HKAFs obtained by Valcke and Krishnan [21] for each exposure routes taken separately. Abbreviations: Amet = amount metabolized for 24 hours and normalized to liver volume ( $\mu \mathrm{g} / 24 \mathrm{~h} . \mathrm{L}$ of liver); $\mathrm{AUC}=$ area under the arterial blood concentration versus time curve $(\mu \mathrm{g} .24 \mathrm{~h} / \mathrm{L}) ;$ met $=$ circulating metabolite; $\mathrm{pc}=$ parent compound; spop = subpopulation; VI $=$ variability index as the ratio of the 95th percentile on the median in adult (VI) or in subpopulation $\left(\mathrm{VI}_{\text {spop }}\right)$. 


\subsection{Variability in the LEQ Values}

\subsubsection{LEQ Based on Absorbed Dose}

Table 4 shows the distribution of the LEQ value in each subpopulation according to the absorbed dose of each contaminant under study during the multi-route exposure. In adults, elderly and PW, the inhalation route contributes the most to the absorbed dose of chloroform and TCE, followed by DW ingestion and dermal contact. This is also true in neonates and children for PERC, but not for chloroform and TCE, for which ingestion and inhalation's ranks are inverted. For the multi-route exposure, mean BW-adjusted LEQ values are greater in neonates regardless of the contaminant considered (0.129-0.134 L/kg BW), as compared to any other subpopulation. In terms of absolute values however, the highest LEQs are computed for PW (4.1-5.6 L). Overall, mean LEQ values for the multi-route scenario are greater for chloroform $(4.1 \mathrm{~L}$ in a $70 \mathrm{~kg}$ adult), followed closely by TCE $(4.0 \mathrm{~L})$ and further by PERC $(3.6 \mathrm{~L})$. The absolute LEQ values obtained using the 95th percentile value of BW-adjusted LEQ do not increase tremendously, given the relatively low intra-group variability in absorbed dose.

Table 4. Variability of chemical-specific LEQ in each subpopulation based on the absorbed dose for the multi-route exposure scenario.

\begin{tabular}{|c|c|c|c|c|c|}
\hline \multirow{2}{*}{$\begin{array}{l}\text { LEQ distributions (L/kg BW) } \\
\text { Contaminant } \\
\text { Exposure route }\end{array}$} & \multicolumn{5}{|c|}{ Subpopulation } \\
\hline & $\begin{array}{l}\text { Adults } \\
(70 \mathrm{~kg}) \\
\end{array}$ & $\begin{array}{c}\text { Neonates } \\
(4 \mathrm{~kg}) \\
\end{array}$ & $\begin{array}{c}\text { Children } \\
(10 \mathrm{~kg}) \\
\end{array}$ & $\begin{array}{l}\text { Elderly } \\
(70 \mathrm{~kg}) \\
\end{array}$ & $\begin{array}{c}\text { Pregnant women } \\
\left(_{(82.5 \mathrm{~kg})}{ }^{(b)}\right. \\
\end{array}$ \\
\hline \multicolumn{6}{|l|}{ Chloroform } \\
\hline Inhalation (mean, CV) & $0.023,21 \%$ & $0.045,25 \%$ & $0.035,18 \%$ & $0.023,21 \%$ & $0.028,23 \%$ \\
\hline Dermal (mean, CV) & $0.015,13 \%$ & $0.039,21 \%$ & $0.027,12 \%$ & $0.015,13 \%$ & $0.013,12 \%$ \\
\hline Ingestion (mean, $\mathrm{CV}$ ) & $0.020,22 \%$ & $0.050,28 \%$ & $0.048,17 \%$ & $0.022,21 \%$ & $0.022,21 \%$ \\
\hline Multi-route (MR) (mean, CV) & $0.058,19 \%$ & $0.134,24 \%$ & $0.110,15 \%$ & $0.061,18 \%$ & $0.063,19 \%$ \\
\hline MR LEQ for BW (mean, 95th perc.) ${ }^{(\mathrm{a})}$ & $\underline{4.06,5.48}$ & $\underline{0.54,0.78}$ & $\underline{1.10,1.37}$ & $\underline{4.25,5.64}$ & $\underline{5.16,6.91}$ \\
\hline \multicolumn{6}{|l|}{ Trichloroethylene } \\
\hline Inhalation (mean, CV) & $0.027,21 \%$ & $0.052,25 \%$ & $0.040,18 \%$ & $0.027,21.0 \%$ & $0.032,24 \%$ \\
\hline Dermal (mean, CV) & $0.011,13 \%$ & $0.029,18 \%$ & $0.020,12 \%$ & $0.011,12 \%$ & $0.010,11 \%$ \\
\hline Ingestion (mean, CV) & $0.020,22 \%$ & $0.053,25 \%$ & $0.047,17 \%$ & $0.022,21.0 \%$ & $0.025,19 \%$ \\
\hline Multi-route (MR) (mean, CV) & $0.058,20 \%$ & $0.134,24 \%$ & $0.107,15 \%$ & $0.060,19 \%$ & $0.067,19 \%$ \\
\hline MR LEQ for BW (mean, 95th perc.) $)^{(\mathrm{a})}$ & $\underline{4.04,5.49}$ & $\underline{0.54,0.79}$ & $\underline{1.07,1.36}$ & $\underline{4.23,5.75}$ & $\underline{5.56,7.00}$ \\
\hline \multicolumn{6}{|l|}{ Tetrachloroethylene } \\
\hline Inhalation (mean, CV) & $0.030,22 \%$ & $0.058,23 \%$ & $0.044,18 \%$ & $0.030,21 \%$ & $0.036,23 \%$ \\
\hline Dermal (mean, CV) & $0.012,14 \%$ & $0.029,22 \%$ & $0.021,12 \%$ & $0.012,13 \%$ & $0,011,12 \%$ \\
\hline Ingestion (mean, CV) & $0.010,21 \%$ & $0.042,23 \%$ & $0.033,15 \%$ & $0.011,17 \%$ & $0.010,19 \%$ \\
\hline Multi-route (MR) (mean, CV) & $0.051,18 \%$ & $0.129,22 \%$ & $0.098,14 \%$ & $0.053,18 \%$ & $0.057,19 \%$ \\
\hline MR LEQ for BW (mean, 95th perc.) ${ }^{(\mathrm{a})}$ & $\underline{3.60,4.69}$ & $\underline{0.52,0.74}$ & $\underline{0.98,1.21}$ & $\underline{3.70,4.90}$ & $\underline{4.71,6.35}$ \\
\hline
\end{tabular}

Notes: (a) obtained by multiplying the BW-adjusted LEQ value by the indicated BW. (b) Pregnant women's BW is based on the mean $\mathrm{BW}$ for an adult women as per the $\mathrm{P}^{3} \mathrm{M}$ database to which the mean increase in $\mathrm{BW}$ during pregnancy (as per ICRP [31]) was added. Abbreviations: $\mathrm{BW}=$ body weight; $\mathrm{CV}=$ coefficient of variation; $\mathrm{LEQ}=$ litre-equivalent; $\mathrm{MR}=$ multi-route; $\mathrm{MR} \mathrm{LEQ}=$ multi-route litre-equivalent. 


\subsubsection{LEQ Based on Internal Dose Metrics}

Table 5 shows the distribution of the LEQ values in each subpopulation according to internal DMs of each contaminant under study during the multi-route exposure. Inhalation contributes the most to the $\mathrm{AUC}_{\mathrm{pc}}$-based LEQ in every subpopulation, followed by dermal exposure except in neonates for TCE and in children for TCE and PERC. Ingestion contributes the most to metabolite-based LEQs for chloroform and TCE, whereas inhalation route contributes the most in the case of PERC. The contribution of dermal exposure to metabolite-based LEQs is always the lowest, except for PERC in adults, $\mathrm{PW}$ and elderly. Multi-route LEQ values based on $\mathrm{AUC}_{\mathrm{pc}}$ are always greater in neonates on a BW-basis (means of $0.190-0.405 \mathrm{~L} / \mathrm{kg} \mathrm{BW}$ ) but are greater in terms of absolute values in PW (means of 11.5-28.6 L), followed by adults and the elderly, who share similar values. The same is true on the basis of the other DM, with ranges of absolute mean LEQ values for PW and adults of 3.7-6.6 and 3.0-5.8, respectively, on the basis of Amet and of 4.3-11.9 and 3.5-9.2 based on $\mathrm{AUC}_{\text {met. }}$ The consideration of the 95th percentile value of BW-adjusted LEQs does not significantly change the value observed given a relatively low variability, except in the case of metabolite-based LEQ for PERC (Table 5). Actually, PERC exhibits the greatest value of metabolite-based LEQ values (9.2 and 5.8 in adults on the basis of $\mathrm{AUC}_{\text {met }}$ and Amet, respectively) as compared to the other contaminants, while LEQ based on $\mathrm{AUC}_{\mathrm{pc}}$ for chloroform was the highest (mean of $23.5 \mathrm{~L}$ in adults, as compared to 8.8 $\mathrm{L}$ and $8.7 \mathrm{~L}$ for TCE and PERC, respectively).

\section{Discussion}

The goal of the present work was to evaluate the inter-individual variability of internal dosimetry and LEQ values during multi-route exposure to three known DWCs. To do so, the model described previously [21] was used given its capability to use age- and gender- specific equations to define physiological parameters, thus reflecting the inter-individual variability in the critical determinants of toxicokinetics [52,53]. In this regard, the results obtained herein are consistent with the known subpopulation-specific differences in these determinants. Indeed, in neonates, greater-than-adult blood concentrations of parent compound (and TCA resulting from highly metabolized TCE) is likely explained by a greater intake on a BW-basis (Figures 1,2) [53], whereas children's greater TCA levels from the low (thus enzyme-limited) metabolism of PERC likely result from the age-related differences in clearance combined with greater-than-adult intake. In addition, differences in TCA blood levels in the elderly and PW as compared to adults are consistent with the respective renal functions in these subpopulations [20,26]. Overall, the results taken together suggest that the LEQs on the basis of absorbed dose or metabolic dose metrics simulated in this study are comparable to the values used in setting the guideline values for these DWCs. 
Table 5. Variability of chemical-specific LEQ in each subpopulation based on internal dose metrics for the multi-route exposure scenario.

\begin{tabular}{|c|c|c|c|c|c|c|c|c|}
\hline \multirow{3}{*}{$\begin{array}{l}\text { Subpopulation } \\
\text { metrics } \\
\text { Exposure route }\end{array}$} & \multicolumn{8}{|c|}{ LEQ distributions in each subpopulation (L/kg BW) } \\
\hline & \multicolumn{2}{|c|}{ Chloroform } & \multicolumn{3}{|c|}{ Trichloroethylene } & \multicolumn{3}{|c|}{ Tetrachloroethylene } \\
\hline & 24-h $\mathrm{AUC}_{\mathrm{pc}}$ & 24-h Amet & 24-h $\mathrm{AUC}_{\mathrm{pc}}$ & 24-h AUC $_{\text {met }}$ & 24-h Amet & 24-h $\mathrm{AUC}_{\mathrm{pc}}$ & 24-h $\mathrm{AUC}_{\text {met }}$ & 24-h Amet \\
\hline \multicolumn{9}{|l|}{ Adults (70 kg) } \\
\hline Inhalation (mean, CV) & $0.200,16 \%$ & $0.016,22 \%$ & $0.076,17 \%$ & $0.023,17 \%$ & $0.017,22 \%$ & $0.078,39 \%$ & $0.084,50 \%$ & $0.048,100 \%$ \\
\hline Dermal (mean, CV) & $0.113,18 \%$ & $0.009,15 \%$ & $0.029,20 \%$ & $0.009,18 \%$ & $0.007,18 \%$ & $0.028,21 \%$ & $0.028,46 \%$ & $0.017,47 \%$ \\
\hline Ingestion (mean, CV) & $0.022,55 \%$ & $0.020,24 \%$ & $0.020,40 \%$ & $0.018,13 \%$ & $0.020,25 \%$ & $0.019,15 \%$ & $0.020,46 \%$ & $0.020,50 \%$ \\
\hline Multi-route (MR), (mean, CV) & $0.335,16 \%$ & $0.045,19 \%$ & $0.125,18 \%$ & $0.050,13 \%$ & $0.043,21 \%$ & $0.124,19 \%$ & $0.132,49 \%$ & $0.082,47 \%$ \\
\hline MR LEQ for BW (mean, 95th) & $23.5,29.9$ & $3.2,4.3$ & $8.8,11.6$ & $3.5,4.3$ & $3.0,4.2$ & $\underline{8.7,11.4}$ & $9.2,17.8$ & $5.8,6.3$ \\
\hline \multicolumn{9}{|l|}{ Neonates (4 kg) } \\
\hline Inhalation (mean, $\mathrm{CV}$ ) & $0.192,16 \%$ & $0.028,29 \%$ & $0.100,14 \%$ & $0.040,33 \%$ & $0.031,39 \%$ & $0.094,2 \%$ & $0.096,66 \%$ & $0.054,69 \%$ \\
\hline Dermal (mean, CV) & $0.138,17 \%$ & $0.020,30 \%$ & $0.049,18 \%$ & $0.020,35 \%$ & $0.015,40 \%$ & $0.044,14 \%$ & $0.043,67 \%$ & $0.026,69 \%$ \\
\hline Ingestion (mean, CV) & $0.075,55 \%$ & $0.048,31 \%$ & $0.063,32 \%$ & $0.044,32 \%$ & $0.046,41 \%$ & $0.052,10 \%$ & $0.043,70 \%$ & $0.042,71 \%$ \\
\hline Multi-route (MR), (mean, CV) & $0.405,22 \%$ & $0.096,28 \%$ & $0.212,19 \%$ & $0.104,32 \%$ & $0.092,39 \%$ & $0.190,4 \%$ & $0.182,66 \%$ & $0.122,70 \%$ \\
\hline MR LEQ for BW (mean, 95th) ${ }^{(a)}$ & $1.6,2.3$ & $\underline{0.4,0.6}$ & $\underline{0.9,1.1}$ & $\underline{0.4,0.6}$ & $\underline{0.4,0.6}$ & $\underline{0.8,0.8}$ & $\underline{0.7,1.7}$ & $\underline{0.5,1.2}$ \\
\hline \multicolumn{9}{|l|}{ Children (10 kg) } \\
\hline Inhalation (mean, CV) & $0.270,12 \%$ & $0.022,10 \%$ & $0.106,11 \%$ & $0.031,16 \%$ & $0.025,18 \%$ & $0.085,8 \%$ & $0.079,35 \%$ & $0.046,37 \%$ \\
\hline Dermal (mean, CV) & $0.176,13 \%$ & $0.015,13 \%$ & $0.049,14 \%$ & $0.014,16 \%$ & $0.011,16 \%$ & $0.037,14 \%$ & $0.033,39 \%$ & $0.020,37 \%$ \\
\hline Ingestion (mean, CV) & $0.056,34 \%$ & $0.047,17 \%$ & $0.054,24 \%$ & $0.044,10 \%$ & $0.045,19 \%$ & $0.046,9 \%$ & $0.043,34 \%$ & $0.043,35 \%$ \\
\hline Multi-route (MR), (mean, CV) & $0.500,12 \%$ & $0.084,16 \%$ & $0.209,12 \%$ & $0.089,11 \%$ & $0.081,16 \%$ & $0.167,8 \%$ & $0.155,36 \%$ & $0.110,36 \%$ \\
\hline MR LEQ for BW (mean, 95th) ${ }^{(\mathrm{a})}$ & $5.0,6.0$ & $\underline{0.8,1.1}$ & $2.1,2.5$ & $0.9,1.1$ & $\underline{0.8,1.1}$ & $1.7,1.9$ & $1.6,2.6$ & $\underline{1.1,1.8}$ \\
\hline \multicolumn{9}{|l|}{ Elderly (70 kg) } \\
\hline Inhalation (mean, CV) & $0.202,15 \%$ & $0.016,21 \%$ & $0.077,17 \%$ & $0.023,17 \%$ & $0.018,21 \%$ & $0.077,16 \%$ & $0.088,48 \%$ & $0.047,47 \%$ \\
\hline Dermal (mean, CV) & $0.114,18 \%$ & $0.009,16 \%$ & $0.029,20 \%$ & $0.009,18 \%$ & $0.007,18 \%$ & $0.028,21 \%$ & $0.028,48 \%$ & $0.017,47 \%$ \\
\hline Ingestion (mean, CV) & $0.025,48 \%$ & $0.023,20 \%$ & $0.023,35 \%$ & $0.021,11 \%$ & $0.021,24 \%$ & $0.021,13 \%$ & $0.023,44 \%$ & $0.021,50 \%$ \\
\hline Multi-route (MR), (mean, CV) & $0.339,16 \%$ & $0.048,19 \%$ & $0.129,18 \%$ & $0.053,13 \%$ & $0.045,20 \%$ & $0.126,16 \%$ & $0.138,47 \%$ & $0.085,48 \%$ \\
\hline MR LEQ for BW (mean, 95 th) ${ }^{(a)}$ & $23.7,30.7$ & $3.4,4.5$ & $9.0,11.9$ & $3.7,4.5$ & $3.2,4.3$ & $\underline{8.8,11.3}$ & $9.7,18.8$ & $\underline{6.0,11.6}$ \\
\hline \multicolumn{9}{|l|}{ Pregnant women (82.5 kg) } \\
\hline Inhalation (mean, CV) & $0.227,14 \%$ & $0.018,24 \%$ & $0.090,14 \%$ & $0.024,18 \%$ & $0.019,25 \%$ & $0.097,12 \%$ & $0.095,45 \%$ & $0.053,49 \%$ \\
\hline Dermal (mean, CV) & $0.098,18 \%$ & $0.008,15 \%$ & $0.026,20 \%$ & $0.007,19 \%$ & $0.005,19 \%$ & $0.027,20 \%$ & $0.025,48 \%$ & $0.015,47 \%$ \\
\hline Ingestion (mean, CV) & $0.024,46 \%$ & $0.021,23 \%$ & $0.023,34 \%$ & $0.021,13 \%$ & $0.021,24 \%$ & $0.022,11 \%$ & $0.024,42 \%$ & $0.023,48 \%$ \\
\hline Multi-route (MR), (mean, CV) & $0.347,14 \%$ & $0.046,20 \%$ & $0.139,16 \%$ & $0.052,14 \%$ & $0.045,22 \%$ & $0.146,12 \%$ & $0.144 .44 \%$ & $0.091,46 \%$ \\
\hline MR LEQ for BW (mean, 95th) ${ }^{(\mathrm{a})}$ & $28.6,35.8$ & $3.8,5.3$ & $11.5,14.5$ & $4.3,5.2$ & $3.7,5.3$ & $12.1,14.6$ & $11.9,22.0$ & $6.6,12.3$ \\
\hline
\end{tabular}

Notes: (a) obtained by multiplying the BW-adjusted LEQ value by the indicated BW. Abbreviations: Amet, amount metabolized during 24 hours normalized to liver volume ( $\mu \mathrm{g} / 24 \mathrm{~h} . \mathrm{L}$ of liver); AUC, area under the arterial blood concentration vs time curve $(\mu \mathrm{g} .24 \mathrm{~h} / \mathrm{L})$; BW, body weight; CV, coefficient of variation; met, circulating metabolite; pc, parent compound; LEQ, litre-equivalent; MR, multi-route; MR LEQ, multi-route litre-equivalent. 
Current results are also consistent with the premise that the variability of internal dosimetry during multi-route exposure is within the range of the variability measures obtained for each route taken separately. Indeed, the VI values reported in Table 3 are generally within the range of the routespecific human kinetic adjustment factors (HKAF) obtained in previous work [21]. The exceptions are VI obtained in children on the basis of Amet of chloroform (2.05 versus range of 1.1-1.8) and TCE (1.94 versus range of 1.1-1.8), as well as in neonates on the basis of $\mathrm{AUC}_{\mathrm{pc}}$ of TCE (3.12 versus range of 2.2-3.1). Presumably, this is due to the significantly greater water ingestion rate, on a BW basis, in neonates and children as compared to adults, which was not typically accounted for by the HKAF for oral exposure [21]. When the hepatic metabolism overcomes the increased intake, as occurs in children, it results in a greater amount of parent compound being metabolized and a corresponding Amet-based VI. The VI for adults exceeding the $\mathrm{HKAF}$ range in the previous work based on $\mathrm{AUC}_{\text {met }}$ for PERC (2.18 versus range of 2.0-2.1) is likely the result of inherent variations from one MC simulation to another. Overall and regardless of the DM considered, the intra-subpopulation variability appeared rather low, as shown by the various CV obtained for LEQ values (Tables 4-5). Exceptions were with the metabolite-based DM of PERC (Table 5). Presumably, this exception is due to the low levels of metabolite generated by the biotransformation of PERC, which makes them more sensitive to any variation in the determinants of metabolism kinetics.

The results of the current study with regard to the LEQ value obtained in an average $70 \mathrm{~kg}$ adult based on the absorbed dose corresponds very well with the values obtained in other studies. In particular, the mean LEQ values for multi-route exposure to chloroform $(4.1 \mathrm{~L})$ and TCE $(4.0 \mathrm{~L})$ are identical to the values obtained by Krishnan and Carrier [18], which were retained by Health Canada $[14,15]$ in its determination of DWG for these contaminants. They are also comparable to the values obtained by Haddad et al. [9] for a 30 min shower, i.e., 4.65 and $4.54 \mathrm{~L}$ for chloroform and TCE, respectively. The inhalation of vapors during showering contributed to 1.71 and $1.95 \mathrm{~L}$ for chloroform and TCE respectively, while corresponding numbers in this study are 1.61 and $1.89 \mathrm{~L}$. Dermal contact during showering with water containing chloroform and TCE was reported to contribute 1.44 and 1.08 LEQ in Haddad et al. [9] compared to 1.05 and 0.77 LEQ in the present study.

Based on internal dose, the results obtained also correspond well to the values of Haddad et al. [9], as the mean multi-route LEQ values based on $\mathrm{AUC}_{\mathrm{pc}}$ were 23.5 and $8.8 \mathrm{~L}$ for chloroform and TCE in the current study, as compared to 24.0 and $8.5 \mathrm{~L}$. Based on Amet, the corresponding values were 3.2 and 3.0 L as compared to Haddad et al.'s 3.69 and 3.57 L [9]. No LEQ values were calculated for PERC by Rao and Brown [11], but the maximum blood concentration at the end of the $30 \mathrm{~min}$ exposure to water containing $1 \mathrm{mg} / \mathrm{L}$ of PERC via the dermal and inhalation routes only $(11-13 \mu \mathrm{g} / \mathrm{L})$ corresponds roughly to the two-thirds of the maximum venous blood concentration obtained in this study with the adult model $(18 \mu \mathrm{g} / \mathrm{L})$, for corresponding exposure (not shown).

Differences in dose-metrics and chemical-specific LEQ values can be explained based on toxicokinetic mechanisms. Indeed, greater LEQ based on $\mathrm{AUC}_{\mathrm{pc}}$ than on the absorbed dose can be explained by the fact that during inhalation and dermal exposure, chemicals are not subject to the hepatic first pass effect, as opposed to when entering the body through ingested water. Thus, a greater dose reaches bloodstream and $\mathrm{AUC}_{\mathrm{pc}}$-based LEQ increases correspondingly (Table 5). This difference is not accounted for when considering only the absorbed dose to establish LEQ. The effect is stronger 
for chloroform than TCE, as chloroform is more extensively metabolized and presents a slower oral absorption rate $\left(\mathrm{K}_{\mathrm{o}}\right)$ such that the hepatic metabolic capacity is not overwhelmed.

The effect of the first-pass metabolism on the LEQ depends upon the dose metric chosen for the assessment. Since a greater amount of parent compound is subject to metabolism during ingestion than when inhaled or absorbed by dermal contact, multi-route LEQ values are likely to be smaller when based on the amount metabolized than on the absorbed dose. This reasoning is however conditional to quick oral absorption. Otherwise, such as for PERC, the LEQ values based on metabolite-based DM depends of the hepatic metabolism that occurs because of the income of parent compound in the blood via the hepatic artery from the systemic circulation rather than from the gut content via the portal vein. As a result, the metabolite-based LEQs are greater than those based solely on the absorbed doses (Table 5), due to higher amounts of parent compound being metabolized during inhalation and dermal exposure.

The toxic moiety on which the LEQ values are based needs to be assessed appropriately, should the results be used for regulatory purposes. Thus, even though high LEQ values were obtained in the present study on the basis of $\mathrm{AUC}_{\mathrm{pc}}$, the adverse effects underlying the VTR of these chemicals are attributed to the metabolite DM [38,43,47,54], for which LEQ values were lower than the values considered by the regulatory agencies [13-16]. Also, the data, and time span covered by the respective age range, for each subpopulation, have to be considered in relation to the duration for which the guidelines are aimed to provide coverage [55].

Several sources of uncertainties are associated with the present study. First, bathroom exposure duration (30 $\mathrm{min}$ ) appears to be a major one since it directly impacts the total dose absorbed, but this assumption errs on the side of greater LEQ values and safety due to greater contributions by dermal and inhalation routes. Second, the $\mathrm{K}_{\mathrm{o}}$ values were extrapolated from animal data for chloroform and PERC and this is a fundamental issue since it strongly influences the internal dose metrics for ingestion and thus the LEQ values. There might also be some uncertainty relating to the use of the same value for partition coefficients (PC) in the PBPK models for all subpopulations despite the fact that tissue composition varies somewhat with age and physiological state [20,52,53]. However, the data from Mahle et al. [56] have suggested that PC values do not vary significantly with age. Third, the results of the sensitivity analyses presented also pointed out that several physiological determinants also impact the toxicokinetics and internal dosimetry during multi-route exposure. Focusing to get better estimates of these parameters would translate into corresponding certainty in the results obtained herein, in particular for highly sensitive parameters, for which the impact varied as a function of the chemical and subpopulation considered. For example, a negative sensitivity index for Qp in enzymeimpaired neonates for poorly metabolized PERC is due to the main contribution of pulmonary clearance to overall systemic clearance whereas for highly metabolized chloroform, blood-flow limited hepatic clearance is the main contributor to total systemic clearance. As a result, Qp rather contributes to the intake of chloroform, as shown by a positive sensitivity index, in the same way as it does for each chemical in adults. Fourth and finally, variability in BW-adjusted water intake was not accounted for in the MC simulations, but this variability is likely to be more reflective of differences in personal habits and environmental conditions rather than variability in the physiological and metabolic capacities among people. Future work integrating probabilistic models of human activity pattern, environmental distribution and phamacokinetics might facilitate the simulation of LEQ distributions 
associated with various multi-route exposure scenarios in subpopulations of interest. However, advanced statistical tools and algorithms for interpreting and dissecting the contributions of the various sources of variability should be in place to facilitate a meaningful interpretation of the MC simulations of LEQ distributions.

\section{Conclusions}

This study has for the first time systematically examined the variability of DM for DWCs during multi-route exposure in various subpopulations. It has also confirmed that the LEQ values determined based on these DM vary significantly. These considerations should be accounted for in future works regarding the determination of drinking water guidelines for contaminants that present a significant potential for multi-route exposure.

\section{Acknowledgements}

Financial support from the Programme stratégique de formation des IRSC et du RRSPQ en recherche transdisciplinaire sur les interventions de santé publique: Promotion, Prévention et Politiques Publiques (4P) is ackowledged (M.V.).

\section{References}

1. Sidhu, K.S. Standard setting processes and regulations for environmental contaminants in drinking water: state versus federal needs and viewpoints. Regul. Toxicol. Pharmacol. 1991, 13, 293-308.

2. Jo, W.K.; Weisel, C.P.; Lioy, P.J. Chloroform exposure and the health risk associated with multiple uses of chlorinated tap water. Risk Anal. 1990, 10, 581-585.

3. Jo, W.K.; Weisel, C.P.; Lioy, P.J. Routes of chloroform exposure and body burden from showering with chlorinated tap water. Risk Anal. 1990, 10, 575-580.

4. Weisel, C.P.; Jo, W.K. Ingestion, inhalation, and dermal exposures to chloroform and trichloroethene from tap water. Environ. Health Perspect. 1996, 104, 48-51.

5. Xu, X.; Weisel, C.P. Dermal uptake of chloroform and haloketones during bathing. J. Expo. Anal. Environ. Epidemiol. 2005, 15, 289-296.

6. Xu, X.; Weisel, C.P. Human respiratory uptake of chloroform and haloketones during showering. J. Expo. Anal. Environ. Epidemiol. 2005, 15, 6-16.

7. Backer, L.C.; Ashley, D.L.; Bonin, M.A.; Cardinali, F.L.; Kieszak, S.M.; Wooten, J.V. Household exposures to drinking water disinfection by-products: Whole blood trihalomethane levels. J. Expo. Anal. Environ. Epidemiol. 2000, 10, 321-326.

8. Buteau, S.; Valcke, M. Probabilistic human health risk assessment for quarterly exposure to high chloroform concentrations in drinking water distribution network of the province of Quebec, Canada. J. Toxicol. Environ. Health A 2010, 73, 1626-1644.

9. Haddad, S.; Tardif, G.C.; Tardif, R. Development of physiologically based toxicokinetic models for improving the human indoor exposure assessment to water contaminants: trichloroethylene and trihalomethanes. J. Toxicol. Environ. Health A 2006, 69, 2095-2136. 
10. Levesque, B.; Ayotte, P.; Tardif, R; Ferron, L.; Gingras, S.; Schlouch, E.; Gingras, G.; Levallois, P.; Dewailly, E. Cancer risk associated with household exposure to chloroform. J. Toxicol. Environ. Health A 2002, 65, 489-502.

11. Rao, H.V.; Brown, D.R. A physiologically based pharmacokinetic assessment of tetrachloroethylene in groundwater for a bathing and showering determination. Risk Anal. 1993, 13, 37-49.

12. Rao, H.V.; Ginsberg, G.L. A physiologically-based pharmacokinetic model assessment of methyl t-butyl ether in groundwater for a bathing and showering determination. Risk Anal. 1997, 17, 583-598.

13. Public Health Goal for Trichloroethylene in Drinking Water; Pesticide and Environmental Toxicology Branch OoEHRAH 2009; California Environmental Protection Agency: Sacramento, CA, USA, 2009.

14. Health Canada. Guidelines for Canadian Drinking Water Quality: Supporting DocumentationTrichloroethylene; Water Quality and Health Bureau: Ottawa, Canada, 2005.

15. Health Canada. Guidelines for Canadian Drinking Water Quality: Supporting DocumentationTrihalomethanes; Water Quality and Health Bureau: Ottawa, Canada, 2006.

16. Health Canada. Guidelines for Canadian Drinking Water Quality: Supporting DocumentationTetrachloroethylene; Water Quality and Health Bureau: Ottawa, Canada, 1995.

17. Chemical-Specific Adjustment Factors (CSAFs) for Interspecies Differences and Human Variability: Guidance Document for the Use of Data in Dose/Concentration-Response Assessment; Report No.: WHO/IPCS/01.4; World Health Organisation (WHO): Geneva, Switzerland, 2005.

18. Krishnan, K.; Carrier, R. Approaches for evaluating the relevance of multiroute exposures in establishing guideline values for drinking water contaminants. J. Environ. Sci. Health C. Environ. Carcinog. Ecotoxicol. Rev. 2008, 26, 300-316.

19. Brochu, P.; Ducré-Robitaille, J.F.; Brodeur, J. Physiological daily inhalation rates for free-living pregnant and lactating adolescents and women aged 11 to 55 years, using data from doubly labelled water measurements for use in health risk assessment. Human Ecol. Risk. Assess. 2006, 12, 702-735.

20. Faustman, E.M.; Ribeiro, P. Pharmacokinetic consideration in developmental toxicity. In Developmental Toxicology: Risk Assessment and the Future; Hood, R.D., Ed.; Van Nostrand Reinhold: New York, NY, USA, 1990; pp. 109-136.

21. Valcke, M.; Krishnan, K. Evaluation of the impact of the exposure route on the human kinetic adjustment factor. Regul. Toxicol. Pharmacol. 2010, doi:10.1016/j.yrtph.2010.10.008.

22. Haddad, S.; Pelekis, M.; Krishnan, K. A methodology for solving physiologically based pharmacokinetic models without the use of simulation softwares. Toxicol. Lett. 1996, 85, 113-126.

23. Thomas, R.S.; Bigelow, P.L.; Keefe, T.J.; Yang, R.S. Variability in biological exposure indices using physiologically based pharmacokinetic modeling and Monte Carlo simulation. Am. Ind. Hyg. Assoc. J. 1996, 57, 23-32.

24. Tan, Y.M.; Liao, K.H.; Clewell, H.J., III. Reverse dosimetry: interpreting trihalomethanes biomonitoring data using physiologically based pharmacokinetic modeling. J. Expo. Sci. Environ. Epidemiol. 2007, 17, 591-603. 
25. Taniguchi, H.; Oguro, A.; Koyama, H.; Masuyama, M.; Takahashi, T. Analysis of models for quantification of arterial and portal blood flow in the human liver using PET. J. Comput. Assist. Tomogr. 1996, 20, 135-144.

26. Sarangapani, R.; Gentry, P.R.; Covington, T.R.; Teeguarden, J.G.; Clewell, H.J., III. Evaluation of the potential impact of age- and gender-specific lung morphology and ventilation rate on the dosimetry of vapors. Inhal. Toxicol. 2003, 15, 987-1016.

27. Johnsrud, E.K.; Koukouritaki, S.B.; Divakaran, K.; Brunengraber, L.L.; Hines R.N.; McCarver, D.G. Human hepatic CYP2E1 expression during development. J. Pharmacol. Exp. Ther. 2003, 307, 402-407.

28. Lipscomb, J.C,; Teuschler, L.K.; Swartout, J.; Swan, G.E.; Snawder, J.E. Variance of microsomal protein and cytochrome P450 2E1 and 3A forms in adult human liver. Toxicol. Mech. Meth. 2003, 13, 45-51.

29. Price, P.S.; Conolly, R.B.; Chaisson, C.F.; Gross, E.A.; Young, J.S.; Mathis, E.T.; Tedder, D.R. Modeling interindividual variation in physiological factors used in PBPK models of humans. Crit. Rev. Toxicol. 2003, 33, 469-503.

30. DeWoskin, R.S.; Thompson, C.M. Renal clearance parameters for PBPK model analysis of early lifestage differences in the disposition of environmental toxicants. Regul Toxicol Pharmacol 2008, 51, 66-86.

31. ICRP. Annals of the ICRP. ICRP Publication 89. Ann. ICRP 2002, 32, 5-265.

32. Nelson, W.E. Textbook of Pediatrics, 15th ed.; W.B. Sauders Company: New York, NY, USA, 1991.

33. Exposure Factor Handbook; US Environmental Protection Agency: Washington, DC, USA, 1997.

34. Estimated Per Capita Water Ingestion and Body Weight in the United States-An Update; Report No.: EPA-822-R-00-001; US Environmental Protection Agency: Washington, DC, USA, 2004.

35. Corley, R.A.; Mendrala, A.L.; Smith, F.A.; Staats, D.A.; Gargas, M.L.; Conolly, R.B.; Andersen, M.E.; Reitz, R.H. Development of a physiologically based pharmacokinetic model for chloroform. Toxicol. Appl. Pharmacol. 1990, 103, 512-527.

36. Poulin, P.; Krishnan, K. A biologically-based algorithm for predicting human tissue: blood partition coefficients of organic chemicals. Hum. Exp. Toxicol. 1995, 14, 273-280.

37. Klingler, M.; Demmelmair, H.; Larque, E.; Koletzko, B. Analysis of FA contents in individual lipid fractions from human placental tissue. Lipids 2003, 38, 561-566.

38. Toxicological Profile for Chloroform; Agency for Toxic Substances and Disease Registry: Atlanta, GA, USA, 1997.

39. Clewell, H.J.; Gentry, P.R.; Kester, J.E.; Andersen, M.E. Evaluation of physiologically based pharmacokinetic models in risk assessment: An example with perchloroethylene. Crit. Rev. Toxicol. 2005, 35, 413-433.

40. Gearhart, J.M.; Mahle, D.A.; Greene, R.J.; Seckel, C.S.; Flemming, C.D.; Fisher, J.W.; Clewell, H.J., III. Variability of physiologically based pharmacokinetic (PBPK) model parameters and their effects on PBPK model predictions in a risk assessment for perchloroethylene (PCE). Toxicol. Lett. 1993, 68, 131-144. 
41. Clewell, H.J.; III; Gentry, P.R.; Covington, T.R.; Gearhart, J.M. Development of a physiologically based pharmacokinetic model of trichloroethylene and its metabolites for use in risk assessment. Environ. Health Perspect. 2000, 108, 283-305.

42. Soucek, B.; Vlachova, D. Excretion of trichloroethylene metabolites in human urine. Br. J. Ind. Med. 1960, 17, 60-64.

43. Toxicological Profile for Trichloroethylene; Agency for Toxic Substances and Disease Registry: Atlanta, GA, USA, 1997.

44. McKone, T.E. Human exposure to volatile organic compounds in household tapwater: the indoor inhalation pathway. Environ. Sci. Technol. 1987, 21, 1194-1201.

45. Gargas, M.L.; Burgess, R.J.; Voisard, D.E.; Cason, G.H.; Andersen, M.E. Partition coefficients of low-molecular-weight volatile chemicals in various liquids and tissues. Toxicol. Appl. Pharmacol. 1989, 98, 87-99.

46. Toxicological Profile for Tetrachloroethylene; Agency for Toxic Substances and Disease Registry: Atlanta, GA, USA, 1997.

47. McKone, T.E.; Knevzovitch, J.P. The transfer of trichloroethylene (TCE) from shower to indoor air: experimental measurements and their implications. J. Air Waster Manage. Assoc. 1991, 40, 282-286.

48. Lindstrom, A.B.; Highsmith, V.R.; Buckley, T.J.; Pate, W.J.; Michael L.C. Gasolinecontaminated ground water as a source of residential benzene exposure: a case study. J. Expo. Anal. Environ. Epidemiol. 1994, 4, 183-195.

49. Statistics Canada. Canadian community health survey, cycle 2.1. Statistics Canada, 2003. Available online: http://www.statcan.gc.ca/cgi-bin/imdb/p2SV.pl?Function=getSurvey\&SurvId $=3226 \&$ SurvVer $=0 \&$ SDDS $=3226 \&$ InstaId $=15282 \&$ InstaVer $=2 \&$ lang $=$ en $\& \mathrm{db}=\mathrm{imdb} \& \mathrm{adm}=8 \& \mathrm{di}$ $\mathrm{s}=2$ (accessed on 2 February 2010).

50. Meek, M.E.; Renwick, A.; Ohanian, E.; Dourson, M.; Lake, B.; Naumann, B.D.; Vu, V. Guidelines for application of chemical-specific adjustment factors in dose/concentration-response assessment. Toxicology 2002, 181-182, 115-120.

51. Dorne, J.L.; Renwick, A.G. The refinement of uncertainty/safety factors in risk assessment by the incorporation of data on toxicokinetic variability in humans. Toxicol. Sci. 2005, 86, 20-26.

52. Clewell, H.J.; Teeguarden, J.; McDonald, T.; Sarangapani, R.; Lawrence, G.; Covington, T.; Gentry, R.; Shipp, A. Review and evaluation of the potential impact of age- and gender-specific pharmacokinetic differences on tissue dosimetry. Crit. Rev. Toxicol. 2002, 32, 329-389.

53. Valcke, M.; Krishnan, K. Physiologically based pharmacokinetic modeling in the risk assessment of developmental toxicants. In Developmental Toxicology; Hansen, D.K., Abbott B.D., Eds.; Informa Healthcare: New York, NY, USA, 2009; pp. 243-274.

54. Integrated Risk Information System. US Environmental Protection Agency, 2010. Available online: http://cfpub.epa.gov/ncea/iris/index.cfm?fuseaction=iris.showSubstanceList\&list_type= alpha\&view $=\mathrm{C}($ accessed on 15 November 2010). 
55. 2009 Edition of the Drinking Water Standards and Health Advisories; EPA/822/R/09/011; Office of Water, US Environmental Protection Agency: Washington, DC, USA, 2009. Available online: http://water.epa.gov/action/advisories/drinking/upload/dwstandards2009.pdf (accessed on 15 November 2010).

56. Mahle, D.A.; Gearhart, J.M.; Grigsby, C.C.; Mattie, D.R.; Barton, H.A.; Lipscomb, J.C.; Cook, R.S. Age-dependent partition coefficients for a mixture of volatile organic solvents in Sprague-Dawley rats and humans. J. Toxicol. Environ. Health A 2007, 70, 1745-1751.

(C) 2010 by the authors; licensee MDPI, Basel, Switzerland. This article is an open access article distributed under the terms and conditions of the Creative Commons Attribution license (http://creativecommons.org/licenses/by/3.0/). 